\title{
Trends and predictors of early ablation for Atrial Fibrillation in a Nationwide population under age 65: a retrospective observational study
}

Robert N. D'Angelo ${ }^{1}$, Rahul Khanna ${ }^{2}$, Robert W. Yeh', Laura Goldstein ${ }^{3}$, Iftekhar Kalsekar², Stephen Marcello ${ }^{4}$, Patricia Tung ${ }^{1}$ and Peter J. Zimetbaum ${ }^{1 *}$

\begin{abstract}
Background: Catheter ablation (CA) has emerged as an effective treatment for symptomatic atrial fibrillation (AF). However practice patterns and patient factors associated with referral for CA within the first 12 months after diagnosis are poorly characterized. This study examined overall procedural trends and factors predictive of catheter ablation for newly-diagnosed atrial fibrillation in a young, commercially-insured population.

Methods: A large nationally-representative sample of patients age 20 to 64 from years 2010 to 2016 was studied using the IBM MarketScan ${ }^{\oplus}$ Commercial Database. Patients were included with a new diagnosis of AF in the inpatient or outpatient setting with continuous enrollment for at least 1 year pre and post index visit. Patients were excluded if they had prior history of AF or had filled an anti-arrhythmic drug (AAD) in the pre-index period.

Results: Early CA increased from $5.0 \%$ in 2010 to $10.5 \%$ in 2016. Patients were less likely to undergo CA if they were located in the Northeast (OR: 0.80, Cl: 0.73-0.88) or North Central (OR: 0.91, Cl: 0.83-0.99) regions (compared with the West), had higher $\mathrm{CHA}_{2} \mathrm{DS}_{2}$-VASc scores, or had Charlson Comorbidity Index (CCI) score of 3 or greater (OR: $0.61 ; \mathrm{Cl}: 0.51-0.72)$.

Conclusions: CA within 12 months for new-diagnosed AF increased significantly from 2010 to 2016, with most patients still trialed on an AAD prior to CA. Patients are less likely to be referred for early CA if they are located in the Northeast and North Central regions, have more comorbidities, or higher $\mathrm{CHA}_{2} \mathrm{DS}_{2}-\mathrm{VASC}$ scores.
\end{abstract}

Keywords: Atrial fibrillation, Catheter ablation, Rhythm control

\section{Background}

Atrial fibrillation (AF) can present with severe symptoms, thromboembolic events, and hemodynamic instability that leads to morbidity and mortality and frequent hospitalizations [1-4]. Patients who are highly

\footnotetext{
* Correspondence: pzimetba@bidmc.harvard.edu

${ }^{1}$ Richard A. and Susan F. Smith Center for Outcomes Research, Division of Cardiology, Beth Israel Deaconess Medical Center, 185 Pilgrim Road, Boston, MA 02215, USA

Full list of author information is available at the end of the article
}

symptomatic from AF are candidates for a rhythm control strategy. Rhythm control strategies have traditionally focused on anti-arrhythmic drugs (AADs), although studies have shown that these drugs have numerous side effects and many patients do not durably maintain sinus rhythm $[1,5,6]$. Catheter ablation (CA) has emerged as a viable alternative to AADs that may better maintain sinus rhythm or reduce AF burden.

Emerging evidence has suggested that CA may be more effective than AADs for improving symptoms of

(c) The Author(s). 2020 Open Access This article is licensed under a Creative Commons Attribution 4.0 International License, which permits use, sharing, adaptation, distribution and reproduction in any medium or format, as long as you give appropriate credit to the original author(s) and the source, provide a link to the Creative Commons licence, and indicate if changes were made. The images or other third party material in this article are included in the article's Creative Commons licence, unless indicated otherwise in a credit line to the material. If material is not included in the article's Creative Commons licence and your intended use is not permitted by statutory regulation or exceeds the permitted use, you will need to obtain permission directly from the copyright holder. To view a copy of this licence, visit http://creativecommons.org/licenses/by/4.0/. The Creative Commons Public Domain Dedication waiver (http://creativecommons.org/publicdomain/zero/1.0/) applies to the data made available in this article, unless otherwise stated in a credit line to the data. 
$\mathrm{AF}$, although the effect of CA on hard patient outcomes including hospitalization, adverse events, and mortality is unclear. Several randomized controlled trials have sought to assess the effectiveness of $\mathrm{CA}$ as a first-line therapy for AF and found $\mathrm{CA}$ resulted in decreased $\mathrm{AF}$ burden and improved subjective quality of life compared to AADs [7-10]. A recent retrospective study of younger, commercially-insured patients found that CA resulted in fewer hospitalizations for AF and heart failure [11]. Additionally, there are several ongoing clinical trials to assess the safety and efficacy of early ablation for AF in patients who have not been treated with AADs (NCT03118518, NCT02686749).

These studies have not addressed the optimal timing of CA, although a prospective study showed that shorter duration between AF diagnosis and CA reduced rate of $\mathrm{AF}$ recurrence and adverse cardiac remodeling, using NT-proBNP and left atrial size as surrogate measures [12]. In particular, patients who underwent CA within 1 year of AF diagnosis (referred to as "early CA" for study purposes), had the greatest chance of long-term maintenance of sinus rhythm. Yet, recent consensus guidelines continue to recommend trial of Class I or Class III anti-arrhythmic prior to CA for AF [13]. Additionally, many US payer-based guidelines mandate treatment with an antiarrhythmic drug prior to referral for catheter ablation, which may delay time to $\mathrm{CA}$ and reduce its long-term effectiveness.

It is not well known how this information has translated to real-world practice, particularly with regard to how the frequency of early CA is changing over time, regional differences in practice, and patient specific factors that lead to referral for early CA. This study assesses practice patterns for treatment of atrial fibrillation within a young nationally-representative and commercially-insured population.

\section{Methods}

\section{Study population}

A retrospective observational study was conducted using medical and prescription claims data from the IBM MarketScan ${ }^{\circ}$ Commercial Database. The Commercial database includes a nationally-representative, Health Information Portability and Accountability Act of 1996 (HIPAA) compliant sample of patients with employersponsored private health insurance [14]. The study was exempt from Institutional Review Board approval at Beth Israel Deaconess Medical Center.

Patients were identified for inclusion in the study using International Classification of Diseases, 9th revision and 10th revision, Clinical Modification (ICD-9/ ICD-10) diagnostic codes for AF (427.21, I48.X). Patients age 20 to 64 with at least two different visits either in the inpatient or outpatient setting with a primary diagnosis of AF within 3 months from January 1, 2010 to September 30, 2016 were included. The use of 2 different visits was used in order to increase the specificity of the AF diagnosis. The date of first AF diagnosis was considered as 'index AF diagnosis'. Patients needed to be continuously enrolled for at least 12 months pre-index and 12 months post-index period to be included. Because the goal was to diagnose only those patients with new onset atrial fibrillation, patients were excluded if they had any diagnosis of AF in the pre-index period or if they had filled an AAD in the pre-index period. The following AADs were identified: amiodarone, disopyramide, dofetilide, dronedarone, flecainide, quinidine, propafenone, and sotalol.

\section{Covariates and outcomes}

Patient demographics included age, sex, region (Northeast, North Central, South, and West), insurance type (comprehensive, Exclusive Provider Organization (EPO) or Health Maintenance Organization (HMO), Point of Service (POS) with capitation, Preferred Provider Organization (PPO), Consumer-Drive Health Plan (CDHP) or High-Deductible Health Plan (HDHP)). Patient clinical characteristics included Charlson Comorbidity Index (CCI), $\mathrm{CHA}_{2} \mathrm{DS}_{2}$-VASc Score, and previously defined Elixhauser comorbidities [15-17]. The primary outcome of interest was CA within the first year after AF diagnosis, identified using the following ICD-9/ICD-10 codes (ICD-93734; ICD-1002553ZZ, 02563ZZ, 02573ZZ, 02583ZZ, 025K3ZZ, 025L3ZZ, 025M3ZZ, 025S3ZZ, 025T3ZZ) and CPT codes (93,651, 93,656). Additional outcome variables included number of AADs trialed, anticoagulants used, and Direct Current Cardioversions (DCCV). The following oral anticoagulants were included: warfarin, apixaban, dabigatran, rivaroxaban, and edoxaban.

\section{Statistical analysis}

We first examined rates of CA within the first year of index for each year of the study, as well as preceding AAD use, and examined temporal trends using an XYZ test. We then developed a multivariable logistic regression model to determine factors associated with CA within the first year. Covariates included patient demographics, CCI Score, $\mathrm{CHA}_{2} \mathrm{DS}_{2}$-VASc score, and comorbidities. Results are presented as odds ratios with 95\% confidence intervals. All analyses were performed with SAS for Windows, version 9.4 at a 2-tailed significance of $P<0.05$.

\section{Results}

Clinical characteristics

Initial and final sample sizes after applying study inclusion and exclusion criteria are shown in Fig. 1. Of 335, 


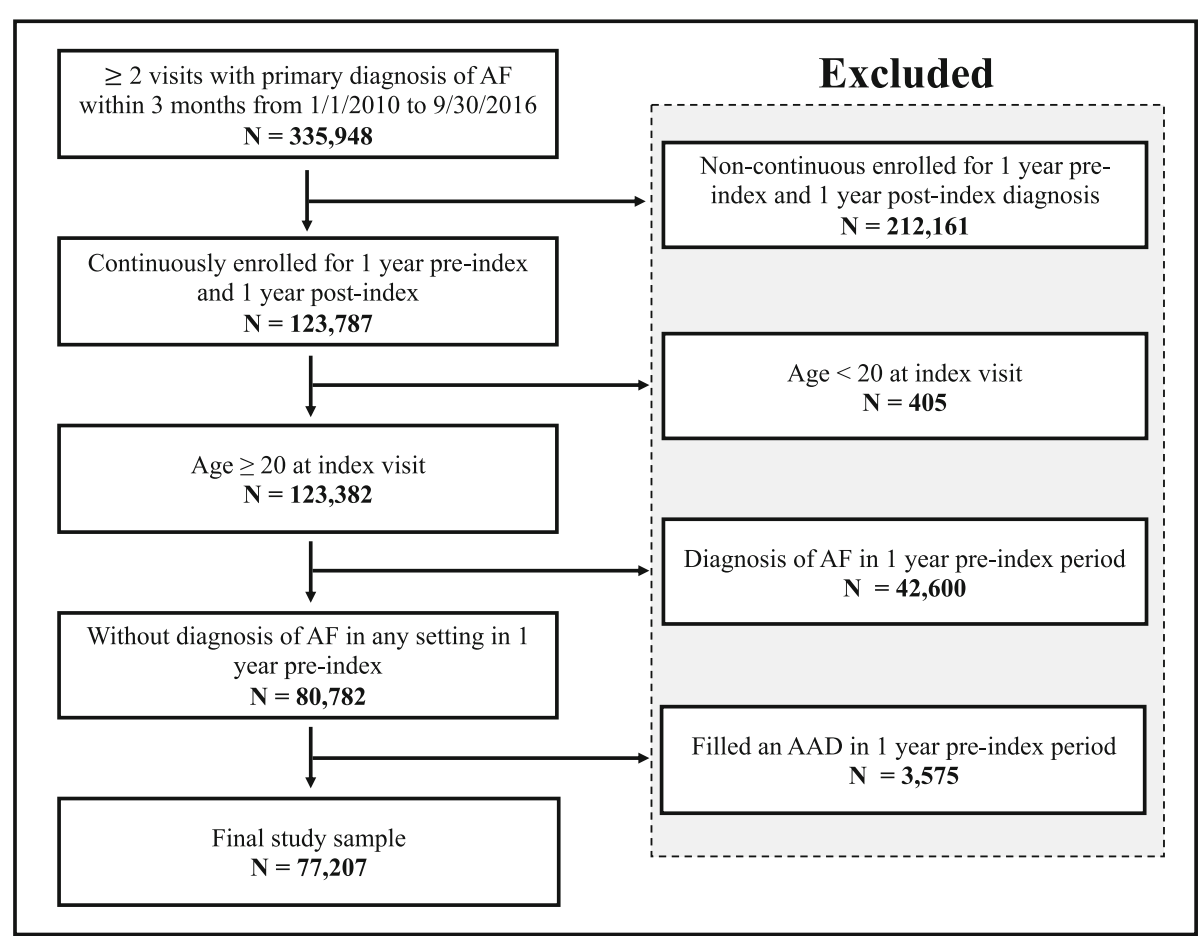

Fig. 1 Central Illustration: Flow diagram - Selection of study participants from years 2010-2016

948 patients who met initial screening criteria, 77,207 patients with a new diagnosis of AF were included in the final study sample. Characteristics of patients included in the study are presented in Table 1 . Mean age was $58.8( \pm 8.4), 67 \%$ were male, and the majority $(77 \%)$ were diagnosed in the outpatient setting. The cohort drew most heavily from the South (38\%), followed by North Central (25\%), Northeast (19\%), and West (16\%), reflective of data-sharing agreements with commercial insurance plans rather than prevalence of atrial fibrillation within these regions. Most patients were insured by PPO health plans (61\%), followed by EPO/HMO (13\%), with other insurance types less frequently represented.

Almost $60 \%$ of patients had a CCI score of 0 . Fifty-five percent of patients had a $\mathrm{CHA}_{2} \mathrm{DS}_{2}$-VASc score of $1-2$, $31 \%$ had a score of 0 , and the remaining $14 \%$ had a score of 3 or higher. The most common comorbidity was hypertension (46\%), followed by diabetes (18\%). Other clinical characteristics are presented in Table 1.

Twenty-nine percent of patients were trialed on an AAD, and $46 \%$ were started on an anticoagulant within first year of incident AF diagnosis. While $24 \%$ of patients underwent DCCV, only $7 \%$ of patients underwent CA. Additional outcomes are presented in Table 2. For those undergoing $\mathrm{CA}$ in the first year, 59\% of patients were trialed on an AAD prior to undergoing CA, which increased over the study period from $58 \%$ in 2010 to $64 \%$ in 2016.
After implementation of ICD-10 in 2015, the following AF subtypes were recorded: paroxysmal, persistent, chronic, and unspecified. The majority of patients were classified as having either paroxysmal (36\%) or unspecified (56\%) AF, with persistent (5\%) and chronic (2\%) AF rarely represented. The overall prevalence of ablation within these groups was similar, ranging from $9 \%$ in unspecified AF to $15 \%$ for persistent AF, as shown in Fig. 2.

\section{Trends and predictors of early CA}

The proportion of patients who underwent early ablation increased steadily from $5.0 \%$ in 2010 to $10.5 \%$ in 2016 . Temporal trends in early CA are presented in Fig. 3. The odds of undergoing CA within the first year increased significantly over the study period, with patients in 20162.2 times more likely to undergo CA than those in 2010 (Odds ratio [OR]: 2.18; 95\% Confidence Interval [CI]: 1.93-2.46). Patients were less likely to undergo CA if they were located in the Northeast (OR: 0.80, CI: 0.73-0.88) or North Central (OR: 0.91, CI: 0.83-0.99) regions (reference 'West'). Insurance type also affected likelihood of undergoing CA, as patients with PPO (OR: 1.09; CI: 1.01-1.18) or high deductible health plans (OR: 1.16; CI: 1.04-1.29) were more likely to undergo CA.

A number of patient-specific factors were predictive of undergoing early CA. Overall, patients with more comorbidities were less likely to undergo CA. Specifically, 
Table 1 Baseline patient characteristics

\begin{tabular}{|c|c|}
\hline Characteristic & Patients $(n=77,207)$ \\
\hline Age, mean (SD) & $53.8(8.4)$ \\
\hline Male (\%) & $51,570(66.8)$ \\
\hline \multicolumn{2}{|l|}{ US geographic region, n (\%) } \\
\hline Northeast & $14,324(18.6)$ \\
\hline North Central & $19,436(25.2)$ \\
\hline South & $29,661(38.4)$ \\
\hline West & $12,634(16.4)$ \\
\hline Unknown & $1152(1.5)$ \\
\hline \multicolumn{2}{|l|}{ Index Diagnosis, n (\%) } \\
\hline Inpatient & $17,434(22.6)$ \\
\hline Outpatient & $59,773(77.4)$ \\
\hline \multicolumn{2}{|l|}{ Insurance Type, n (\%) } \\
\hline Comprehensive or EPO or $\mathrm{HMO}$ & $13,627(17.7)$ \\
\hline POS \& POS with capitation or PPO & $54,306(70.3)$ \\
\hline CDHP or HDHP & $8145(10.6)$ \\
\hline Unknown & $1129(1.5)$ \\
\hline \multicolumn{2}{|l|}{$\mathrm{CCl}^{\mathrm{a}}, \mathrm{n}(\%)$} \\
\hline Score 0 & $45,921(59.5)$ \\
\hline Score 1-2 & $23,126(30.0)$ \\
\hline Score $\geq 3$ & $8160(10.6)$ \\
\hline \multicolumn{2}{|l|}{$\mathrm{CHA}_{2} \mathrm{DS}_{2}-\mathrm{VASc}, \mathrm{n}(\%)$} \\
\hline Score 0 & $23,675(30.7)$ \\
\hline Score 1-2 & $42,588(55.2)$ \\
\hline Score $\geq 3$ & $10,944(14.2)$ \\
\hline \multicolumn{2}{|l|}{ Comorbidity, n (\%) } \\
\hline Sleep apnea & $8625(11.2)$ \\
\hline Obesity & $7558(9.8)$ \\
\hline Diabetes & $13,651(17.7)$ \\
\hline Hypertension & $35,658(46.2)$ \\
\hline Congestive heart failure & $4964(6.4)$ \\
\hline Cardiomyopathy & $2637(3.4)$ \\
\hline Chronic pulmonary disease & $9333(12.1)$ \\
\hline Renal disease/failure & $2519(3.3)$ \\
\hline Other arrhythmia & $9766(12.7)$ \\
\hline Wolf-Parkinson-White Syndrome & $81(0.1)$ \\
\hline Non-paroxysmal AV nodal tachycardia & $86(0.1)$ \\
\hline Paroxysmal supraventricular tachycardia & $1903(2.5)$ \\
\hline Atrial flutter & $2213(2.9)$ \\
\hline Valvular heart disease & $7178(9.3)$ \\
\hline Congenital heart disease & $718(0.9)$ \\
\hline Hyperthyroidism & $613(0.8)$ \\
\hline Ischemic heart disease & $4584(5.9)$ \\
\hline
\end{tabular}

${ }^{a} \mathrm{CCl}$ Charleston Cormorbidity Index
Table 2 Primary outcomes - Antiarrhythmic medications, anticoagulant medications, cardioversions, and catheter ablation

\begin{tabular}{ll}
\hline Outcomes & Patients $(\mathrm{n}=77,207)$ \\
\hline Antiarrhythmic medication ${ }^{\mathrm{a}}, \mathrm{n}(\%)$ & $55,077(71.3)$ \\
0 & $19,196(24.9)$ \\
1 & $3,934(3.8)$ \\
$2+$ & \\
Anticoagulant medication ${ }^{\mathrm{b}}, \mathrm{n}(\%)$ & $41,479(53.7)$ \\
0 & $32,239(41.8)$ \\
1 & $3,489(4.5)$ \\
$2+$ & $18,875(24.4)$ \\
Direct current cardioversion, $\mathrm{n}(\%)$ & $5,451(7.1)$ \\
Catheter ablation, $\mathrm{n}(\%)$ &
\end{tabular}

anti-arrhythmic medications included: amiodarone, disopyramide, dofetilide, dronedarone, flecainide, quinidine, propafenone, and sotalol

${ }^{b}$ Anticoagulant medications included: warfarin, apixaban, dabigatran, rivaroxaban, and edoxaban

patients with CCI score of 3 or greater (OR: 0.61, CI: 0.51-0.72; reference score 0) or $\mathrm{CHA}_{2} \mathrm{DS}_{2}$-VASc score greater than 0 were significantly less likely to undergo CA. Patients with $\mathrm{CHA}_{2} \mathrm{DS}_{2}$-VASc scores of 3 or greater were least likely to undergo ablation (OR: 0.46 ; CI: 0.38 0.55 ; reference score 0 ). Patients were more likely to undergo ablation if they were male (OR: $1.12, \mathrm{CI}: 1.03-$ 1.22) or had cardiomyopathy (OR: 1.40, CI: $1.09-1.79$ ). Patients with atrial flutter were two times more likely to undergo CA (OR: 2.00, CI: 1.75-2.29), while those with other arrhythmias were $41 \%$ more likely to undergo CA in the first-year post-incident diagnosis of AF (OR: 1.41, CI: 1.30-1.53). Additional factors predictive of early ablation are presented in Fig. 4.

\section{Discussion}

A number of studies have demonstrated the benefits of early referral for $\mathrm{CA}$ in selected patient populations. Single-center studies and randomized-controlled trials have shown that early ablation can lead to improvements in adverse cardiac remodeling, greater success in maintaining sinus rhythm, and decreased need for repeat CA $[12,18]$. Studies have shown that young patients may benefit the most from early ablation, however most observational and retrospective studies have focused on patients older than 65 [19-21]. Our study addresses trends in catheter ablation within a young population and specifically identifies predictors of referral for early ablation.

Despite recognition of the benefits of an early rhythm control strategy in some patients, only $30 \%$ of patients were trialed on an anti-arrhythmic, and an even smaller portion, 7\%, were referred for early CA. This may reflect low arrhythmia burden of newly-diagnosed AF within a young population, or a missed opportunity to avoid long-term sequelae of undertreated AF. Nonetheless, the 


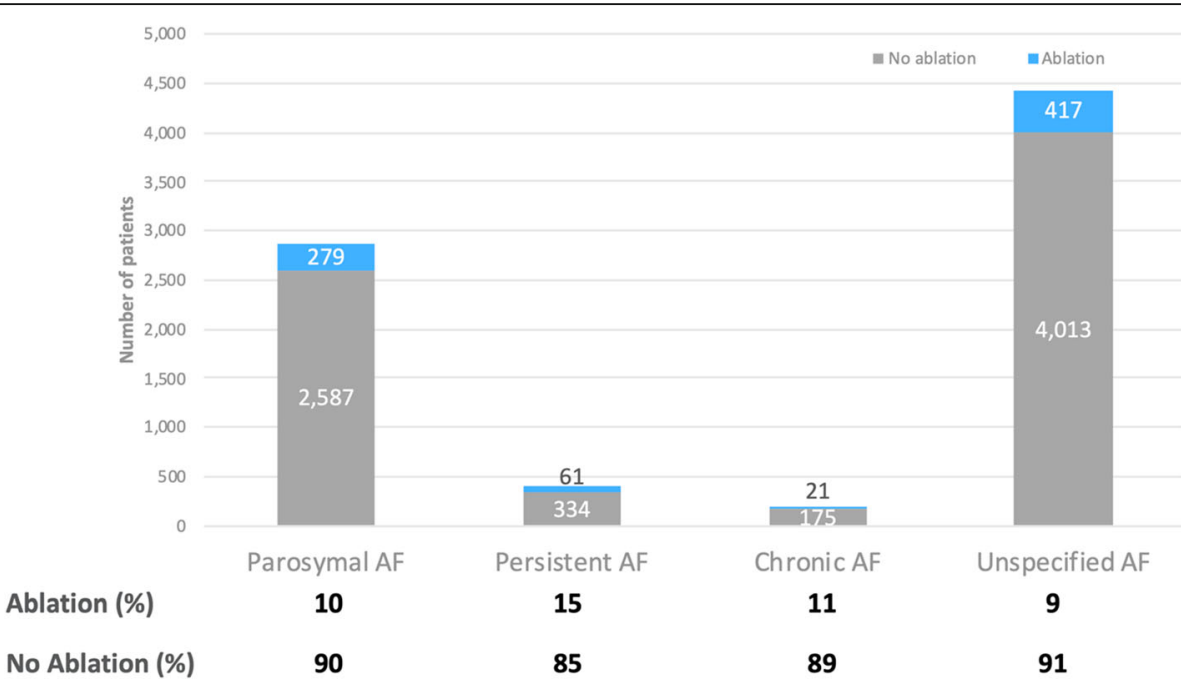

Fig. 2 Classification and Rates of Ablation by ICD-10 AF Subtype

odds of being referred for early ablation increased by 2.2 times over the study period. This suggests the increases in CA shown in other studies are not simply being driven by increased referral of older patients or those who have already been trialed on AADs. Although we were unable to directly measure AF burden, patients diagnosed in the inpatient setting were $12 \%$ more likely to be referred for $\mathrm{CA}$, suggesting severity of AF symptoms were a predictor of early CA.

As AF subtype was recorded after implementation of ICD-10, we investigated whether this affected ablation strategy. We would expect that patients with paroxysmal $\mathrm{AF}$ or persistent AF of short duration would be most likely to benefit from ablation and therefore would be referred at higher rates [12, 22-24]. Yet, the rates of ablation were similar, likely due to inclusion and exclusion criteria that minimized the number of patients with long-standing persistent AF or chronic AF and coding integrity. Overall, the ability to generalize outcomes by AF subtype is limited given a large proportion of patients in the post ICD-10 era are classified as having unspecified AF.

Forty-two percent of patients proceeded to ablation without trialing an AAD in 2010, which decreased to $36 \%$ in 2016. The increase in AAD use prior to ablation likely reflects increased recognition of the benefits of rhythm control in a young population along with insurance mandates to trial an AAD prior to ablation. As

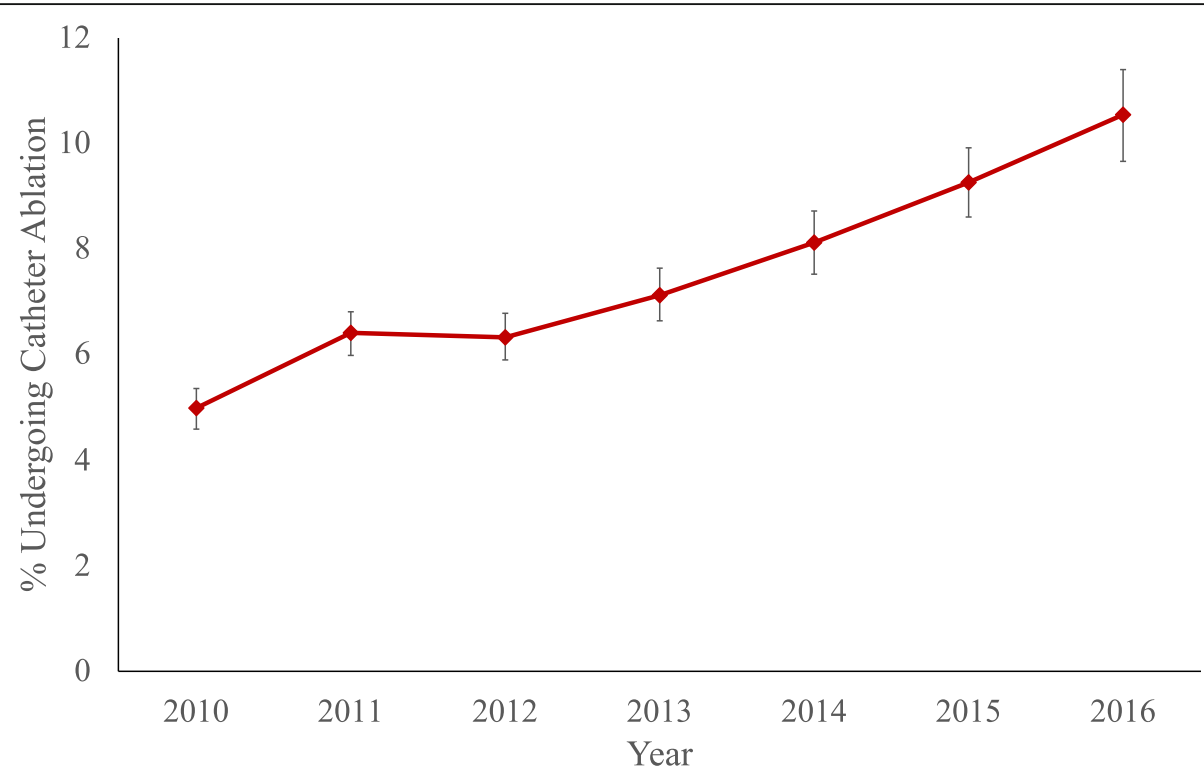

Fig. 3 Growth in early catheter ablation for AF from 2010 to 2016 


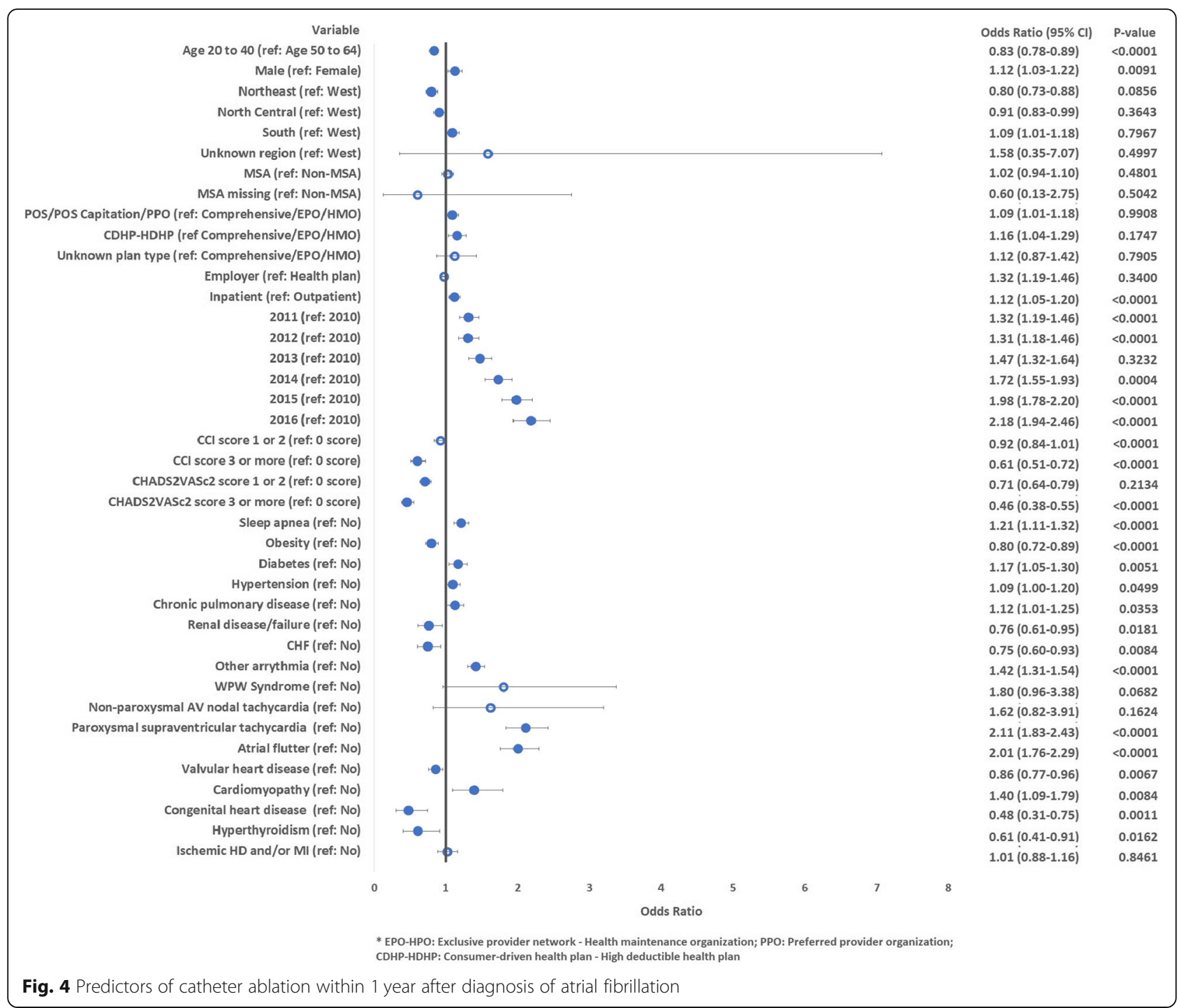

there is increasing recognition that many patients do not have durable responses to treatment with AADs, proceeding with early ablation can lead to improved outcomes and avoid likelihood of repeat ablation [25]. Overall, these findings are compatible given that many younger patients have a short duration of treatment with AADs prior to ablation [20].

Overall, healthier patients were most likely to be referred for ablation, both reflected in $\mathrm{CHA}_{2} \mathrm{DS}_{2}$-VASc score and CCI. Patients with lower $\mathrm{CHA}_{2} \mathrm{DS}_{2}$-VASc scores were more likely to undergo ablation, which could reflect decreased perceived procedural risk or the desire to discontinue anticoagulation after ablation. Further work is required to understand whether patients are discontinuing anticoagulation after ablation. Similar to results found in other studies, fewer patients are treated with anticoagulants than is recommended by guidelines. Only $46 \%$ of patients with a $\mathrm{CHA}_{2} \mathrm{DS}_{2}$-VASc score of $1-$
2 and $60 \%$ of patients with a $\mathrm{CHA}_{2} \mathrm{DS}_{2}$-VASc score of 3 or higher filled a prescription for an anticoagulant in the year after diagnosis. While most comorbidities were negatively associated with early CA, patients with cardiomyopathy were more likely to be referred for CA. Presumably some of these patients had tachycardia-induced cardiomyopathy and benefited from maintenance of normal sinus rhythm or decreased burden of $\mathrm{AF}$, as was shown in the CASTLE-AF Trial [24].

We found significant differences in practice patterns unrelated to patient demographics. Patients located within the Northeast and North Central regions were significantly less likely to be referred for early CA. This mirrors geographic variation seen in other studies of CA as well as cardiac devices more generally [20, 26, 27]. A study of Medicare patients found that ablation was more likely in the South and West, although there were more specific differences within referral regions [20]. Even 
within Europe, studies have shown geographic variation in CA utilization [28]. Further investigation is required to understand the drivers of these differences, which may include physician training networks affecting referral threshold, hospital incentives and payment methods, or patient preferences. Insurance type is also a significant predictor of early ablation. Patients with PPO or high-deductible health plans are more likely to undergo early ablation. Potential explanations include decreased barrier to early electrophysiology referral, different outof-pocket expense, or fewer barriers for trialing alternative treatments prior to proceeding to ablation.

Our study includes a large, nationally-representative sample of commercially insured patients. Our study focuses on a non-elderly adult cohort, which coincides with our understanding of who is likely to benefit from ablation. Given non-uniform adoption of CA, there are opportunities to explore the causes of these differences to ensure more uniform adoption of early ablation.

\section{Study limitations}

Our study has several limitations. Despite its large size, there is year-to-year variation in total patient encounters due to changes in agreements with the commercial vendor. This limits the ability to characterize absolute procedural volume over time, but still permits understanding of likelihood of undergoing CA. Furthermore, there were differences in geographic representation within the dataset due to vendor agreements, with patients in the South and North Central regions more frequently represented. We cannot draw conclusions about the overall prevalence of ablation within these regions, but the factors associated with early ablation should not be affected. Additionally, we were unable to determine whether ablation was successful in maintaining normal sinus rhythm given we used a claims-based dataset, although future work will explore surrogates of successful ablation including repeat ablation and hospitalizations.

Our reliance on diagnosis codes for AF phenotyping and the underlying criteria for incident AF identification could have influenced the study results. While the type of AF (paroxysmal, persistent, permanent) may relate to the benefit of early ablation, this distinction was only implemented in ICD-10 and does not appear reliable or generalizable given the majority of patients were coded as having unspecified AF. Nonetheless, we would expect this distinction to be less relevant within the first year of diagnosis. As our study includes a younger population, the findings cannot be extended to an older population.

\section{Conclusions}

In conclusion, early referral for $\mathrm{CA}$ of $\mathrm{AF}$ in a young population increased from $5.0 \%$ in 2010 to $10.5 \%$ in 2016, with most patients still trialed on an AAD. There is significant geographic variation in utilization of CA, with patients in the Northeast and North Central regions less likely to be referred. Further studies are required to understand the drivers of these differences as well as the impact of early CA on patient outcomes, hospitalization, and treatment cost.

\section{Abbreviations \\ AAD: Anti-arrhythmic drug; AF: Atrial fibrillation; CA: Catheter ablation; $\mathrm{CCl}$ : Charlson comorbidity index; CDHP-HDHP: Consumer-driven health plan - high deductible health plan; DCCV: Direct current cardioversion; EPO- HPO: Exclusive provider network - health maintenance organization; PPO: Preferred provider organization}

\section{Acknowledgements \\ Not applicable.}

\section{Authors' contributions}

All authors have participated in the work and have reviewed and agree with the content of the article. All authors have read and approved the manuscript. RND worked to conceive and design the study, analyze and interpret data, draft and revise the manuscript, and approve the final manuscript. RWY, PJZ conceived and designed the study, helped to draft and revised the manuscript, and approved the final manuscript. RK developed the study protocol, analyzed and interpreted the data, revised the manuscript, and approved the final manuscript. LG, IK, SM, and PT helped with analysis and interpretation of the data, revised the manuscript for important intellectual content, and approved the final manuscript.

\section{Funding \\ None.}

\section{Availability of data and materials}

The data that support the findings of this study are available from IBM Marketscan ${ }^{\oplus}$ database but restrictions apply to the availability of these data, which were used under license and in collaboration with the Healthcare Economics group at Johnson and Johnson for the current study, and so are not publicly available. Data are however available from the authors upon reasonable request and with permission of Johnson and Johnson.

\section{Ethics approval and consent to participate}

The study was exempt from Institutional Review Board approval at Beth Israel Deaconess Medical Center.

\section{Consent for publication}

Not applicable.

\section{Competing interests}

Rahul Khanna, Laura Goldstein, Iftekhar Kalsekar, and Stephen Marcello are employees of Johnson and Johnson and have stock ownership. Robert Yeh reports consulting fees from Biosense Webster and Medtronic, and research grants and consulting fees from Abbott Vascular and Boston Scientific. Al other authors have report that they have no relationships relevant to the contents of this paper to disclose.

\section{Author details}

${ }^{1}$ Richard A. and Susan F. Smith Center for Outcomes Research, Division of Cardiology, Beth Israel Deaconess Medical Center, 185 Pilgrim Road, Boston, MA 02215, USA. ${ }^{2}$ Medical Device Epidemiology and Real World Data Science, Johnson and Johnson, New Brunswick, NJ, USA. ${ }^{3}$ Franchise Health Economics and Market Access, Johnson and Johnson, New Brunswick, NJ, USA. ${ }^{4}$ Medical Safety, Johnson and Johnson, New Brunswick, NJ, USA.

Received: 27 December 2019 Accepted: 24 March 2020

Published online: 06 April 2020

\section{References}

1. Arbelo E, Brugada J, Lundqvist CB, Laroche C, Kautzner J, Pokushalov E, et al. Contemporary management of patients undergoing atrial fibrillation ablation: in-hospital and 1-year follow-up findings from the ESC-EHRA atrial 
fibrillation ablation long-term registry. Eur Heart J. 2017;37(17):ehw564 Available from: https:/academic.oup.com/eurheartj/article-lookup/doi/10.1 093/eurheartj/ehw564. [cited 2017 Jun 10].

2. Calkins H, Reynolds MR, Spector P, Sondhi M, Xu Y, Martin A, et al, Treatment of atrial fibrillation with antiarrhythmic drugs or radiofrequency ablation: two systematic literature reviews and meta-analyses. Circ Arrhythmia Electrophysiol. 2009;2(4):349-61.

3. Hanley CM, Esberg D, Kowey PR. Ablation versus drugs: what is the best first-line therapy for paroxysmal Atrial Fibrillation?: Antiarrhythmic drugs are outmoded and catheter ablation should be the first-line option for all patients with paroxysmal Atrial Fibrillation: con. Circ Arrhythmia Electrophysiol. 2014;7(4):747-54. Available from: http://circep.ahajournals. org/cgi/doi/10.1161/CIRCEP.113.001281.

4. January CT, Wann LS, Alpert JS, Calkins H, Cigarroa JE, Cleveland JC, et al. 2014 AHA/ACC/HRS Guideline for the Management of Patients With Atrial Fibrillation: Executive Summary. Circulation. 2014;130(23):2071-104. Available from: https://www.ahajournals.org/doi/10.1161/CIR.0000000000000040. [cited 2020 Mar 20].

5. Kim E-J, Yin X, Fontes JD, Magnani JW, Lubitz SA, McManus DD, et al. Atrial fibrillation without comorbidities: prevalence, incidence and prognosis (from the Framingham heart study). Am Heart J. 2016;177:138-44 Available from: http://inkinghub.elsevier.com/retrieve/pii/S0002870316300370.

6. Shah RU, Freeman J V., Shilane D, Wang PJ, Go AS, Hlatky MA. Procedural Complications, Rehospitalizations, and Repeat Procedures After Catheter Ablation for Atrial Fibrillation. J Am Coll Cardiol. 2012;59(2):143-9. Available from: https://www.sciencedirect.com/science/article/pii/S073510971104602 X?via\%3Dihub. [cited 2020 Mar 20].

7. Morillo CA, Verma A, Connolly SJ, Kuck KH, Nair GM, Champagne J, et al. Radiofrequency Ablation vs Antiarrhythmic Drugs as First-Line Treatment of Paroxysmal Atrial Fibrillation (RAAFT-2). JAMA. 2014;311(7):692. Available from: http://www.ncbi.nlm.nih.gov/pubmed/24549549. [cited 2019 May 14].

8. Nielsen JC, Johannessen A, Raatikainen P, Hindricks G, Walfridsson H, Pehrson SM, et al. Long-term efficacy of catheter ablation as first-line therapy for paroxysmal atrial fibrillation: 5-year outcome in a randomised clinical trial. Available from: http://heart.bmj.com/. [cited 2019 May 14].

9. Namdar M, Chierchia G-B, Westra S, Sorgente A, Meir ML, Bayrak F, et al. Isolating the pulmonary veins as first-line therapy in patients with lone paroxysmal atrial fibrillation using the Cryoballoon. Europace. 2012;14(2): 197-203. Available from: http://www.ncbi.nlm.nih.gov/pubmed/21937477. [cited 2019 May 14].

10. Tanner H, Makowski K, Roten L, Seiler J, Schwick N, Muller C, et al. Catheter ablation of atrial fibrillation as first-line therapy--a single-centre experience. Europace [Internet]. 2011;13(5):646-53. Available from: http://www.ncbi.nlm. nih.gov/pubmed/21422023. [cited 2019 May 14].

11. Guo J, Nayak HM, Besser SA, Beaser A, Aziz Z, Broman M, et al. Impact of Atrial Fibrillation Ablation on Recurrent Hospitalization A Nationwide Cohort Study. 2019; Available from: https://doi.org/10.1016/j.jacep.2018.10.015 [cited 2019 May 14].

12. Hussein AA, Saliba WI, Barakat A, Bassiouny M, Chamsi-Pasha M, Al-Bawardy R, et al. Radiofrequency Ablation of Persistent Atrial Fibrillation. Circ Arrhythmia Electrophysiol. 2016;9(1). Available from: https://www. ahajournals.org/doi/10.1161/CIRCEP.115.003669. [cited 2019 Mar 15].

13. Calkins H, Hindricks G, Cappato R, Kim Y-H, Saad EB, Aguinaga L, et al. 2017 HRS/EHRA/ECAS/APHRS/SOLAECE expert consensus statement on catheter and surgical ablation of atrial fibrillation: Executive summary. EP Eur. 2018; 20(1):157-208. Available from: https://academic.oup.com/europace/article/2 0/1/157/4158231. [cited 2019 Mar 15].

14. Hansen LG, Chang S. HealtH ReseaRcH Data foR tHe Real WoRID: tHe MaRketscan Databases [Internet]. 2011. Available from: https://truvenhealth. com/portals/0/assets/PH_11238_0612_TEMP_MarketScan_WP_FINAL.pdf. [cited 2019 Mar 1].

15. Lip GYH, Nieuwlaat R, Pisters R, Lane DA, Crijns HJGM. Refining Clinical Risk Stratification for Predicting Stroke and Thromboembolism in Atrial Fibrillation Using a Novel Risk Factor-Based Approach. Chest. 2010:137(2): 263-72. Available from: http://www.ncbi.nlm.nih.gov/pubmed/19762550. [cited 2019 mar 9].

16. Charlson M, Szatrowski TP, Peterson J, Ggld J. VALIDATION OF A COMBINED COMORBIDITY INDEX [Internet]. J Clin Epidemiol. 1994;47. Available from: https://ac-els-cdn-com.ezp-prod1.hul.harvard.edu/08954356 94901295/1-s2.0-0895435694901295-main.pdf?_tid=9ce1756c-32cf-4dbd- 9d0d-d133c067d848\&acdnat=1552173896_f9434f623a3aece2db58bc45394 87817. [cited 2019 Mar 9].

17. Elixhauser A, Steiner C, Harris DR, Coffey RM. Comorbidity Measures for Use with Administrative Data. Vol. 36, Care. 1998. Available from: https://wwwjstor-org.ezp-prod1.hul.harvard.edu/stable/pdf/3766985.pdf?refreqid= excelsior\%3A484f0a2d3f28cdf8ea46a0637e01a34a. [cited 2019 Mar 9].

18. Nielsen JC, Johannessen A, Raatikainen P, Hindricks G, Walfridsson $H$, Pehrson SM, et al. Long-term efficacy of catheter ablation as first-line therapy for paroxysmal atrial fibrillation: 5-year outcome in a randomised clinical trial. Heart. 2017;103(5):368-76. Available from: https://heart.bmj. com/content/103/5/368. [cited 2019 Mar 15].

19. Piccini JP, Sinner MF, Greiner MA, Hammill BG, Fontes JD, Daubert JP, et al. Outcomes of Medicare beneficiaries undergoing catheter ablation for atrial fibrillation. Circulation. 2012;126(18):2200-7. Available from: http://www.ncbi. nlm.nih.gov/pubmed/23019293. [cited 2019 mar 16].

20. Sinner MF, Piccini JP, Greiner MA, Walkey AJ, Wallace ER, Heckbert SR, et al. Geographic variation in the use of catheter ablation for atrial fibrillation among Medicare beneficiaries. Am heart J [Internet]. 2015;169(6):775-82.e2. Available from. http://www.ncbi.nlm.nih.gov/pubmed/26027614. [cited 2019 mar 16].

21. Holmqvist F, Simon D, Steinberg BA, Hong SJ, Kowey PR, Reiffel JA, et al. Catheter Ablation of Atrial Fibrillation in U.S. Community Practice--Results From Outcomes Registry for Better Informed Treatment of Atrial Fibrillation (ORBIT-AF). J Am Heart Assoc. 2015;4(5). Available from: http://www.ncbi. nlm.nih.gov/pubmed/25999401. [cited 2019 mar 16].

22. Verma A, Jiang C, Betts TR, Chen J, Deisenhofer I, Mantovan R, et al. Approaches to Catheter Ablation for Persistent Atrial Fibrillation. N Engl J Med. 2015;372(19):1812-22. Available from: http://www.nejm.org/doi/10.1 056/NEJMoa1408288. [cited 2017 Jun 10].

23. Arbelo E, Brugada J, Hindricks G, Maggioni AP, Tavazzi L, Vardas P, et al. The Atrial Fibrillation Ablation Pilot Study: An European Survey on Methodology and results of catheter ablation for atrial fibrillation conducted by the European Heart Rhythm Association. Eur Heart J. 2014;35(22):1466-78. https://doi.org/10.1093/eurheartj/ehu001.

24. Marrouche NF, Brachmann J, Andresen D, Siebels J, Boersma L, Jordaens L, et al. Catheter Ablation for Atrial Fibrillation with Heart Failure. N Engl J Med. 2018;378(5):417-27. Available from: http://www.nejm.org/doi/10.1056/ NEJMoa1707855. [cited 2019 Mar 18].

25. Allen LaPointe NM, Dai D, Thomas L, Piccini JP, Peterson ED, Al-Khatib SM. Antiarrhythmic drug use in patients. Am J Cardiol [Internet]. 2015;115(3): 316-22. Available from: http://www.ncbi.nlm.nih.gov/pubmed/25491240. [cited 2019 mar 18].

26. Hatfield LA, Kramer DB, Volya R, Reynolds MR, Normand ST. Geographic and Temporal Variation in Cardiac Implanted Electric Devices to Treat Heart Failure. J Am Heart Assoc. 2016;5(8). Available from: https://www. ahajournals.org/doi/10.1161/JAHA.116.003532. [cited 2019 Mar 16].

27. Strom et al. Variation in Mechanical Circulatory Support Use. 2019. Available from: http://ahajournals.org. [cited 2019 Mar 9].

28. Riahi S, Arbelo E, Brugada J, Maggioni A Pietro, Tavazzi L, Vardas P, et al. Regional differences in referral, procedures, and outcome after ablation for atrial fibrillation in Europe: a report from the Atrial Fibrillation Ablation Pilot Registry of the European Society of Cardiology. Europace. 2016;18(2):191200. Available from: https:/academic.oup.com/europace/article-lookup/ doi/10.1093/europace/euv386. [cited 2019 Mar 16].

\section{Publisher's Note}

Springer Nature remains neutral with regard to jurisdictional claims in published maps and institutional affiliations. 